\title{
Commentary: The many roads traveled in tetralogy of Fallot repair
}

\author{
Andrew Well, MD, MPH, and Carlos M. Mery, MD, MPH
}

\footnotetext{
From the Division of Pediatric and Congenital Cardiothoracic Surgery, Department of Surgery and Perioperative Care, University of Texas Dell Medical School, Austin, Tex and Texas Center for Pediatric and Congenital Heart Disease, UT Health Austin/Dell Children's Medical Center, Austin, Tex.

Disclosures: Authors have nothing to disclose with regard to commercial support.

Received for publication Sept 7, 2019; revisions received Sept 7, 2019; accepted for publication Sept 10, 2019; available ahead of print Oct 18, 2019.

Address for reprints: Carlos M. Mery, MD, MPH, Texas Center for Pediatric and Congenital Heart Disease, Dell Children's Medical Center, 4900 Mueller Blvd, Suite 3S.003, Austin, TX 78723 (E-mail: cmery @austin. utexas.edu).

J Thorac Cardiovasc Surg 2020;159:237-8

$0022-5223 / \$ 36.00$

Copyright $(\subset) 2019$ by The American Association for Thoracic Surgery

https://doi.org/10.1016/j.jtcvs.2019.09.024
}

Tetralogy of Fallot (TOF), first described in $1888,{ }^{1}$ is quite possibly the most historically important lesion in pediatric cardiothoracic surgery. The seminal work by Alfred Blalock, Vivian Thomas, and Helen Taussig on palliation ${ }^{2}$ was followed by the first complete repair in 1954 by C. Walton Lillehei. ${ }^{3}$ Despite the vast experience accrued with this lesion, its optimal management remains one of the most hotly debated subjects in our field.

Romeo et $\mathrm{al}^{4}$ have undertaken the monumental task of compiling what is likely the vast majority of the published experience on TOF repair across the globe. Their pooled data show that early outcomes have consistently improved with time and that repair of TOF can be undertaken with relatively low perioperative and long-term mortality. However, there remains significant variability in the management of this lesion, with previous palliative shunts used in 0 to $50 \%$ of reported series and transventricular repairs used 0 to $100 \%$ of the time. This highlights both the technical complexity of TOF repair and the lack of consensus on its best treatment algorithm.

One of the most salient aspects of this study is the persistent linearized probability of death of $0.42 \%$ per year and the $2.26 \%$ yearly rate of reintervention. ${ }^{4}$ These statistics humbly remind us that complete "repair" of TOF, just as most procedures in congenital heart surgery, is truly a palliative procedure. As such, it is incumbent on us to work to minimize the long-term sequelae of our surgical prowess. The study suggests that the "classic" transventricular repair with its large ventricular incision and universal sacrifice of pulmonary valve competency (Figure 1) should give way to newer transatrial/transpulmonary techniques focused on preserving pulmonary valve competency whenever possible and limiting the insult to the ventricle. ${ }^{5,6}$

Many questions remain unanswered. When should we sacrifice the pulmonary valve, and when is it acceptable to leave some degree of obstruction to preserve it? What

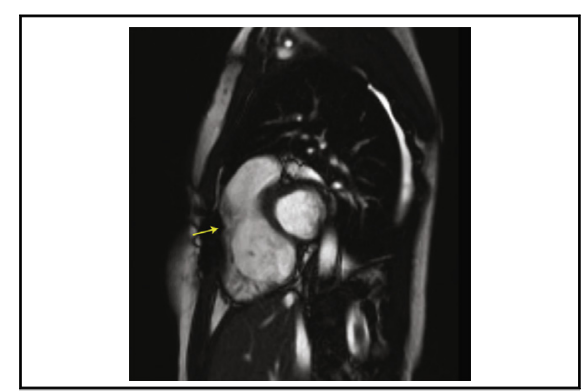

Magnetic resonance imaging after transventricular repair of tetralogy of Fallot.

Central Message

The optimal management of tetralogy of Fallot remains controversial. A comprehensive review of retrospective studies provides important insights, but prospective long-term data are desperately needed.

See Article page 220.

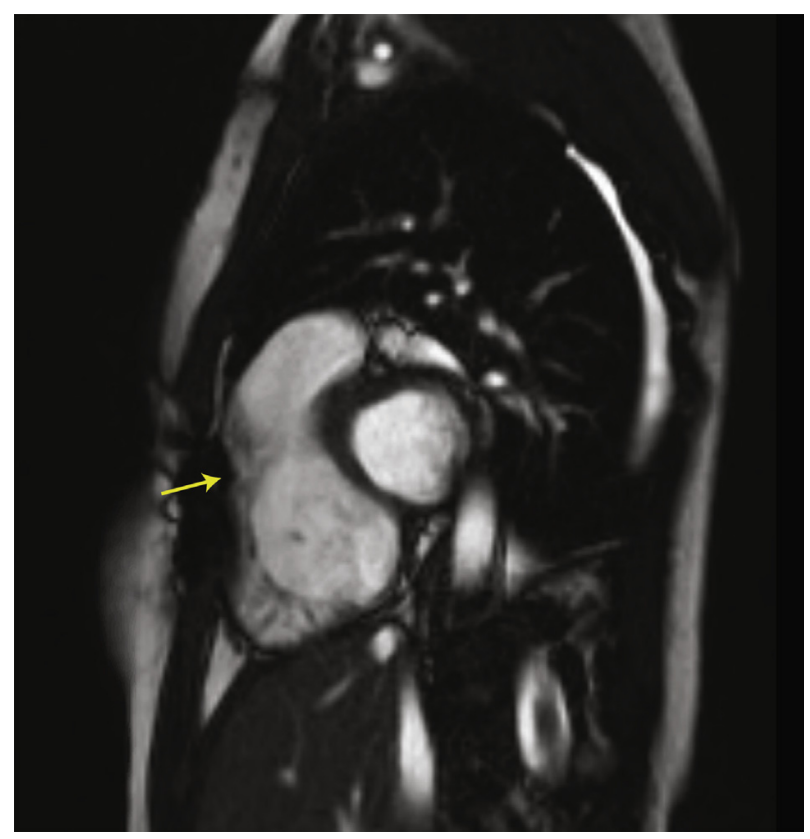

FIGURE 1. Cardiac magnetic resonance imaging of a patient with a previous transventricular repair of tetralogy of Fallot. The extent of the transventricular incision and patch (arrow) leads to free pulmonary insufficiency and a noncontractile right ventricular infundibulum, contributing to further right ventricular dilation and the need for future reintervention. 
is the optimal timing of repair for an asymptomatic infant? Is it better to proceed with complete repair of a symptomatic newborn or to palliate to limit perioperative risk and transannular patching?

The multiple limitations of this study ${ }^{4}$ make it difficult to answer these questions. Some of these limitations include the heterogeneous nature of the studies spanning different philosophies of care; the inclusion of mostly retrospective observational studies, making it difficult to account for important confounding factors; and the inclusion of only patients that lived to undergo a complete "repair". These limitations highlight the need for our field to create more robust mechanisms to prospectively gather long-term data of patients with particular diagnoses, such as TOF, rather than relying on retrospective reviews of retrospective observational procedure-based studies.

Nonetheless, the old adage, "you can't know where you're going without knowing where you've been" holds true for TOF care. This study provides some important insights that can help us decide which road to take next. It is up to us to prospectively assess whether that road is indeed the best road to take.

\section{References}

1. Fallot A. Contribution à l'anatomie pathologique de la maladie bleue (cyanose cardiaque), par le Dr. A. Fallot. Marseille: Impr de Barlatier-Feissat; 1888.

2. Blalock A, Taussig HB. The surgical treatment of malformations of the heart: in which there is pulmonary stenosis or pulmonary atresia. JAMA. 1945;128: 189-202.

3. Lillehei CW, Cohen M, Warden HE, Read RC, Aust JB, Dewall RA, et al. Direct vision intracardiac surgical correction of the tetralogy of Fallot, pentalogy of Fallot, and pulmonary atresia defects; report of first ten cases. Ann Surg. 1955;142: 418-42.

4. Romeo JLR, Etnel JRG, Takkenberg JJM, Roos-Hesselink JW, Helbing WA, van de Woestijne P, et al. Outcome after surgical repair of tetralogy of Fallot: a systematic review and meta-analysis. J Thorac Cardiovasc Surg. 2020;159: 220-36.e8.

5. Morales DL, Zafar F, Heinle JS, Ocampo EC, Kim JJ, Relyea K, et al. Right ventricular infundibulum sparing (RVIS) tetralogy of Fallot repair: a review of over 300 patients. Ann Surg. 2009;250:611-7.

6. Wald RM, Haber I, Wald R, Valente AM, Powell AJ, Geva T. Effects of regional dysfunction and late gadolinium enhancement on global right ventricular function and exercise capacity in patients with repaired tetralogy of Fallot. Circulation. 2009;119:1370-7. 